\title{
Schizophrenic Hong Kong: Postcolonial Identity Crisis in the Infernal Affairs Trilogy
}

\section{Howard Y.F. Choy}

\section{(2) OpenEdition}

\section{Journals}

\section{Electronic version}

URL: http://journals.openedition.org/transtexts/138

DOI: 10.4000/transtexts. 138

ISSN: 2105-2549

\section{Publisher}

Gregory B. Lee

\section{Printed version}

Date of publication: 1 September 2007

Number of pages: 52-66

ISSN: 1771-2084

\section{Electronic reference}

Howard Y.F. Choy, « Schizophrenic Hong Kong: Postcolonial Identity Crisis in the Infernal Affairs

Trilogy », Transtext(e)s Transcultures 跨文本跨文化 [Online], 3 | 2007, Online since 15 October 2009, connection on 30 April 2019. URL : http://journals.openedition.org/transtexts/138 ; DOI : 10.4000/ transtexts.138 


\title{
Schizophrenic Hong Kong: Postcolonial Identity Crisis in the Infernal Affairs Trilogy
}

\author{
HOWARD Y. F. CHOY
}

Michel Foucault avers: «one should totally and absolutely suspect anything that claims to be a return. . . . there is in fact no such thing as a return.» It is, however, in rigid irredentist claims of the return that Hong Kong was handed over from British to Chinese rule in 1997. To the natives of Hong Kong, this postcolonial turn is actually less a decolonization than a recolonization of the capitalist Cantonese city by the mainland Mandarin master. They find themselves helplessly trapped in the dual nationality of overseas British and Chinese nationals. This existential agony is deftly cinematized in the Infernal Affairs trilogy under the disguise of a police epic. The 2002 box-office success and its 2003 prequel and sequel tell a story about an undercover cop and a mafia mole. A crisis of consciousness arises from both the former's desire to regain his true identity and the latter's struggle to become a real cop. The identity crisis is not only about, as critics suggest, split personalities between good and evil, but also political tensions between the colonized and colonizers. This paper argues that the collective failure of identity change before and after the fin de siècle changeover characterizes the Special Administrative Region's schizophrenic return. 


\section{Chineseness/Britishness: Return and Depart}

Michel Foucault avers: «One should totally and absolutely suspect anything that claims to be a return. . . . there is in fact no such thing as a return». ${ }^{1}$ It was, however, in rigid irredentist claims of a «return» that the People's Republic of China (PRC) took over Hong Kong from Great Britain in 1997. Such a «return», or huigui, is at bottom no more than a reversion to sovereignty, and of course sovereign power in this case belongs to the great «motherland» that possesses the Chinese territory, not to the people who actually live there. To the autochthons of the small Hong Kong, this postcolonial (re)turn is actually more a recolonization than a decolonization of the capitalist Cantonese city by the mainland Mandarin master. They find themselves helplessly trapped in the juxtaposition of the dual identities of «overseas» British (as classified and parenthesized in their passports), who have no right of abode in their adopted country, and Chinese nationals, who have no choice in determining their own nationality. For them, the reunification with China as a national integration produces but a nervous breakdown. Being adherents to, or more precisely, abandonees of the fallen British Empire and denizens of the rising People's Republic, how could they possibly redeem Chineseness to reinvent their ethnic identity when the tribal appellation Heung-gong yan, or «Hong Konger», no longer demands a mere cultural identity but also a political subjectivity and social entity $?^{2}$

The concept of Chineseness, however, is problematic. Chinese American neoConfucian Tu Wei-ming (1994: 13-15) has argued that it is the diasporic Chinese individuals who truly understand China, inasmuch as they inherit and disseminate its culture from a critical distance. ${ }^{3}$ Accordingly, Chineseness lies elsewhere than China proper. Tu's analysis assumes that a Chinese identity is to be forged by searching for "Chineseness», not to be taken for granted simply by living in the «motherland». He defines the idea of cultural China in terms of what he calls «three symbolic universes», to wit, the Chinese societies of the PRC, Taiwan, Hong Kong, and Singapore; diasporic Chinese communities, including all Chinatowns throughout the world; and individual ethnic Chinese as well as non-Chinese outside of China, who try to intellectually understand Chinese culture and promote

\footnotetext{
1Paul Rabinow, «Space, Knowledge, and Power: Interview of Michel Foucault», trans. Christian Hubert, Skyline, vol. 20, no7, March 1982, p.20.

2British scholar Matthew Turner (1995: 22-23, 31, 33n26) has aptly argued that Heung-gong yan as "an identity of life-style" is "an ambiguous construction that was more than a 'resident', less than a 'people,'" but on his agenda Hong Kong people must claim themselves "as a 'people', an ethno-cultural sub-group."

${ }^{3}$ Tu Wei-ming, 1994. «Cultural China: The Periphery as the Center», in Tu Wei-ming, ed., The Living Tree: The Changing Meaning of Being Chinese Today, Stanford: Stanford University Press, pp.13-15.
} 
it. Tu admits that his overarching tripartite division is problematic as «Hong Kong, Taiwan, and Singapore have much more in common with the Chinese diaspora than they do with mainland China», and yet «they are grouped together with mainland China as the first symbolic universe because the life orientation in these societies is based on Chinese culture».

I find Tu's argument more convenient than convincing, for it neglects the geopolitical marginality and cultural hybridity of Hong Kong. An island off of the mainland and longi temporis possessio of a Western hegemony, Hong Kong is actually, as $\mathrm{Tu}$ acknowledges it, «at least in spirit, part of the Chinese diaspora». ${ }^{4}$ The diasporized Hong Kong people are neither part of the majority living in the mainland - in the bosom of a supposedly «authentic» Chinese culture, nor are they one of the «minority nationalities» (shaoshu minzu) categorized by the government, who are ethnically different from the Han. Hong Kong people are in-between, both local and global; they are somehow children of a Sino-genetic mother and a foreign foster mother. What makes Hong Kong unique are its at once diasporic mentality within the Chinese cultural world and eccentric «Chineseness» without the modern nation-state known as China - be it the Republic of China or the People's Republic of China, but no longer the Qing empire. I am not suggesting that mainland Chineseness is always fixed (in fact it is already forfeited according to Tu's neoConfucianist and anti-communist agenda) but that the quest(ion) of «Chineseness» in Hong Kong is further complicated by the postcolonial position of the periphery.

Criticizing Tu's conception of cultural China for projecting «a de-centered center» on the periphery, Australian cultural scholar Ien Ang (2000: 287, 282-283) proposes a diasporic paradigm, in which Chineseness «as an open and indeterminate signifier whose meanings are constantly renegotiated and rearticulated» should indicate «many different Chinese identities, not one». ${ }^{5}$ While Rey Chow questions whether the problem can «be resolved simply by way of the act of pluralizing» Chineseness into «so many kinds of Chineseness-es», ${ }^{6}$ Hong Kong cultural critic Lo Kwai-Cheung points out that Tu's reversal of center-periphery hierarchy «may only help to make the cultural and national ideology of Chineseness [a] more powerful, oppressive, and dominating» master code concealing its emptiness and «the void of subjectivity». Instead of putting Hong Kong on a par with mainland China as «the

${ }^{4}$ Tu Wei-ming, p.15.

IIen Ang, "Can One Say No to Chineseness? Pushing the Limits of the Diasporic Paradigm», in Rey Chow, ed., Modern Chinese Literary and Cultural Studies in the Age of Theory: Reimagining a Field, , Durham: Duke University Press, 2000, pp.281-300.

${ }^{6}$ Rey Chow, «Introduction: On Chineseness as a Theoretical Problem», in Modern Chinese Literary and Cultural Studies in the Age of Theory, Durham: Duke University Press, 2000, p.18. 
first symbolic universe», Lo sees Hong Kong's position «both inside and outside of China», hence often shifting toward its Chineseness. His idea of «Hong Kong-styled Chineseness» is worth citing at some length:

«Hong Kong culture itself is by no means fixed. It is instead a process of becoming, generated by various national forces and interests rather than by a single origin. . . . The post-1997 subjectivization of the Hong Kong people as Chinese nationals demonstrates that a different notion of Chineseness can always gratify new demands and that the return of the colony to its motherland might present a challenging perspective from which to examine the supposedly incontestable status of national identity.» ${ }^{7}$

The process of becoming, in my view, is paradoxically also one of departing. Only after a departure from an origin would a transformation be possible; departing is prerequisite to all claims of (be)coming or returning. Departing is distancing, and without a distance perspectives are impossible. It is also, to cite Ang's words once again, «a departure from the mode of demarcating Chineseness through an absolutist oppositioning of authentic and inauthentic, pure and impure, real and fake». ${ }^{8}$ Colonization is a process of departing. Before it was colonized by the British and thus forced to depart from China, Hong Kong had never pondered upon the problem of its Chineseness. And now, when departing from Britain, the issue of becoming Chinese again, or re-Sinicization, cannot be discussed without reference to its Britishness. While Chinese cultural conventions have been well preserved in the enclave, British colonial legacies are ubiquitous: parliamentary democracy in political debates, a legal system symbolized by the Victorian-style Supreme Court, financial services iconized by the Hongkong and Shanghai Bank, everyday practice of afternoon tea with milk, the fascination with Princess Diana, streets named after British princes (e.g., Connaught) or governors (Hennessy, Nathan), and the list goes on. Hong Kongers, to borrow Aihwa Ong's description of overseas Chinese images in the West, are «internal outsiders» in China, whose «deterritorialized modern consciousness», in my view, would never produce a pure Chineseness. ${ }^{9}$ It is in such sense that I would agree with Lo that for Hong Kong the Sino-British clash is not an external difference between contending civilizations but an internal affair within a culture, and that «the city is actually struggling with itself». ${ }^{10}$

${ }^{7}$ Lo Kwai-Cheung, Chinese Face/Off: The Transnational Popular Culture of Hong Kong, Urbana: University of Illinois Press, 2005, pp.2-18.

${ }^{8}$ Ien Ang, «Can One Say No to Chineseness? Pushing the Limits of the Diasporic Paradigm», p.283.

${ }^{9}$ Aihwa Ong, «On the Edge of Empires: Flexible Citizenship among Chinese in Diaspora», Positions: East Asia Cultures Critique, vol.1, n³, Winter, p.770.

${ }^{10}$ Lo Kwai-Cheung, Chinese Face/Off: The Transnational Popular Culture of Hong Kong, p.20. 
This existential agony is deftly cinematized as a neurotic symptom in the Infernal Affairs trilogy, produced by Media Asia, under the veneer of an action thriller. Codirected by Andrew Wai Keung Lau and Alan Siu Fai Mak with the latter's and Felix Man Keung Chong's screenplay, the 2002 blockbuster and its 2003 prequel and sequel tell a story about a mafia mole infiltrating the Hong Kong police force and his counterpart, an undercover cop planted in the triads. A crisis of consciousness arises from both the former's struggle to become a real policeman and the latter's desire to regain his true identity or at least, in his own words, «an identity as a normal man». They are, as the title of Martin Scorsese's remake of the film suggests, «the departed» - departing from where they belong to, from who they are, and from what they want to be. ${ }^{11}$ Striving to end their lives as rats, the spies suffer from schizophrenia as a result of their double espionage agency. The identity crisis is not only about split personality between good and evil, but also political tensions between the colonizer and the colonized, as well as unfulfilled reconciliation between Chineseness and Britishness. The schizophrenic anxious return from being the United Kingdom's «crown jewel» to becoming the Middle Kingdom's Special Administrative Region before and after the fin de siècle changeover characterizes a collective failure of resuming a single, clear-cut identity for a postcolonial global city.

\section{Internal Struggling/Infernal Suffering}

In his review of the cinema of the colonial city with regard to local identity formation, Leung Ping-kwan, a veteran Hong Kong cultural critic and creative writer, once regretfully concluded: «It would be difficult to claim any conscious postcolonial awareness in films produced before and after 1997, especially because Hong Kong cinema has always been commercial in nature with less emphasis on

\footnotetext{
${ }^{11}$ The first film of the trilogy was so successful on the domestic and international markets that Hollywood has produced a remake, The Departed (2006), which won the Academy Awards of Best Motion Picture, Best Director, Best Adapted Screenplay, and Best Film Editing in 2007. Directed by Martin Scorsese and rewritten by William Monahan, The Departed has the story setting shifted from Hong Kong to Boston. While a full-fledged discussion of the new version will have to be taken up on a different occasion, I want to point out here that the American reproduction is very Hollywoodish with only more violent and sexual scenes but a less convincing and profound plot of identity, not to mention its stereotyped and shoddy image of sinister Chinese smugglers employed by the PRC government, the USA's post-cold-war hypothetical foe. Film critic Brian Hu (2006) has observed the Hollywood makers' Sinophobe complex and their attempt to disassociate their adaptation from the original: "By denying the influence of Infernal Affairs, The Departed denies its non-American roots and cultural hybridity." Yet is not the denial also a schizophrenic symptom signifying an American anxiety of Asian influence in the age of globalization?
} 
scripts with social concern».12 Infernal Affairs, however, conceals the question of a postcolonial Hong Kong identity in the twists and turns of a thriller tradition. Inspired by the schizoid story of identity exchange in John Woo's Face/Off (1997), it begins with respective recruitments of secret agents by drug lord Sam Hon (played by Eric Tsang) and police superintendent Wong Chi Shing (Anthony Wong). While Lau Kin Ming (Andy Lau) becomes a fake detective in Wong's team, Chan Wing Yan (Tony Leung) has been an undercover operative inside Sam's crime squad. The parallel fates of Lau and Chan make them mirror images of one another: where the former attempts unscrupulously to cover up his original identity, the latter makes every endeavor to bring himself to light. ${ }^{13}$ Even their student identification numbers at the police training school, 4927 (Lau) and 27149 (Chan), are almost simple reversions of each other. ${ }^{14}$ The two men are one another's double, both having desperate desire to gain a legitimate and eternal identity.

With the plot twisting back and forth between Chan and Lau, the viewer is encouraged to shift ground between the two characters' positions. On the one hand, Chan negotiates with his police handler Wong to end his ten-year masquerade; on the other, Lau is promoted to head the Criminal Intelligence Bureau and transferred to Internal Affairs (pun on the title Infernal Affairs) to ferret out the drug dealer Sam's infiltrator, that is, ironically, himself. As they race to uncover each other, particularly in the back-street scene, it is as if they are chasing after their own identities in an inextricable maze. After Wong has been brutally killed by Sam's underlings, Lau is able to pick up the connection with Chan by using the mobile phone left behind by Wong. The criminal mole and police snitcher co-operate by air, with the aid of Morse code, to capture Sam. Out of a crisis of consciousness rather than conscience, Lau means to renounce his unlawful past as he guns down his mob boss. Yet his illicit background is accidentally discovered when he finally encounters his counterpart in his office.

The most intriguing scene of the crime thriller is when Lau realizes that his secret history is uncovered by Chan. Instead of taking his life, Lau determines to erase Chan's computer file, thus permanently deleting his police identity. Here, as in the

\footnotetext{
${ }^{12}$ Leung Ping-kwan, «Urban Cinema and the Cultural Identity of Hong Kong», in Poshek Fu and David Desser, eds., The Cinema of Hong Kong: History, Arts, Identity, Cambridge: Cambridge University Press, 2000, p249.

${ }^{13}$ Critics have indicated that the innovation of Infernal Affairs in the subject of espionage lies in the counterpoint between the two protagonists. See, for example, Ling 2003: C8.

${ }^{14}$ This is not a coincidence as Chan's number was originally 36877 in the first three drafts of the script. See Mak Siu Fai and Chong Man Keung, Wujiandao qianzhuan: Juben, bianju Iunshu (Infernal Affairs: screenplay with scriptwriters' commentary), 2003, pp.167-169.
} 
plans and counter-plans of the operations on Sam's cocaine deal with a Thai gang earlier in the film, bloody gunfights yield to psychic tensions. ${ }^{15}$ The psychic tension, to be further developed in the third part of the series, becomes a high-concept presentation of identity crisis. Such psychosis arises from the double life of being cat and mouse at the same time. Lau believes that the best way to annihilate Chan is to strip him of his real identity. What he does not understand is: his enemy is but his other, reversed self. Chan makes the same mistake, only more fatally so. He wants his identity back, but will not let Lau go with impunity. It ends up in a tragedy as the «gangster» contrives to arrest the «police». The former is shot dead on the spot by inspector Billy (Gordon Lam), who in turn is slain by Lau immediately after revealing that he used to be Sam's informer, too. As more and more eyes and ears unexpectedly emerge from both camps along the plotline, we realize that the morbidity of the identity illness is so high that it becomes a collective crisis. Chan's failure in his identity readjustment and justification in the final rooftop scene allegorically implies the impossibility of a return to the «original» identity of the Chinese population in Hong Kong prior to the Opium War (1839-42), the Sino-British drug war that resulted in the cession of the harbor. The double identity that disturbs the secret police throughout his life is indicated cinematographically by the close-up image of his corpse and its reflection on the metallic wall inside the elevator, whose dark shaft reappearing in the trilogy is evocative of the infernal motif.

Compared with Chan's destiny, Lau's is rather ambiguous as it generates two endings. In the Hong Kong version, when he walks out from the elevator, he finally announces to his fellows: «I'm a cop». As he appears to have overcome his identity crisis, his fear is only temporarily suppressed and will reemerge as identity neurosis in Infernal Affairs III, which I shall discuss below. An alternate ending is given in the Malaysian/mainland Chinese version, in which inspector Cheung ( $\mathrm{Ng}$ Ting Yip) has detected Lau's criminal identity and arrests him right outside of the elevator. ${ }^{16}$ Film critic Ma Chi attributes the discrepancy to the difference in geocultural background, namely, the pursuits of entertainment and commercial value in Hong Kong and the emphases of ideology and didactic function in the mainland. ${ }^{17}$ While the Mandarin denouement may be a result of official censorship

\footnotetext{
${ }^{15}$ It is untypical of action movies that the first gunfight does not occur until after the middle of the film (sc. 35E) and lasts for only 30 seconds. The climax also reworks Hollywood conventions by replacing actions with a face-off, turning the final confrontation into a conscious contemplation. ${ }^{16}$ The Hong Kong version is the original design according to the first draft of the script. ${ }^{17} \mathrm{Ma}$ Chi, «Wenhua chayi yu chuangzuo jiqiao - Tan Wujiandao Xianggang neidi liang ge jieju» («Cultural Difference and Artistic Technique: On the Two Endings of Infernal Affairs in Hong Kong and the Mainland», Wenwei po, 28 $8^{\text {th }}$ February, 2003, C8.
} 
and moral standards, according to which the evil should never prevail over the good, the Cantonese coda goes beyond the cliché that every bad deed has its just reward to the possibility of an open identity, an identity that is flexible rather than fixable. With his double endings, Lau's identity is not fixed, but mixed. Moreover, Lau's survival only renders Chan's sacrifice senseless and his obsession with a consistent, authentic identity inopportune in the face of rapidly changing realities.

Chan's police identity is not proved until six months after his death, when his appointed psychiatrist Lee Sum Yee (Kelly Chen) finds his file among the personal effects of the deceased headmaster of the cadet. Chan has once revealed his secret to Dr. Lee, who nevertheless thought that he was just kidding. Now, in the last scene of the cop drama, standing in front of Chan's grave, Lee makes farewells to her patient: «How are you, Mr. Policeman?» The woman psychologist's role as Chan's mental mirror cannot be overemphasized. It is during her treatment that Chan wonders whether he is suffering from schizophrenia, and it is she who ultimately recovers his lost identity - though it is too late for him to be reinstated to his original post. In fact, her clinic, the only place he can fall asleep, has become his spiritual home or haven. In like vein, another female character, Mary (Sammi Cheng), also provides her fiancé, Lau, with a new hearth and home. Mary is writing a novel, in which she creates a man with multiple personalities, but she fails to finish it, especially after she learns about Lau's espionage. Both female fringe figures enrich the masculine mafia movie in two profound ways: first, they open up a therapeutic feminine space in the midst of the manic male-dominated mise en scène; second, they compose a metanarrative that foregrounds the problem of identity.

In contrast with the female figures, the father figures Wong and Sam are responsible for the fates of Chan and Lau - that is, the fate of the colonized suggestive of the 1984 Sino-British Joint Declaration that predetermines the city's future. If Wong, father of the former Royal Hong Kong Police Force, represents the remnant British authorities, Sam symbolizes the pre-1997 domestic influence that stays in power in the new age. After Wong as the agent of the colonizer has been undone by Sam, the diametrically opposed moles Lau and Chan work together to get rid of the local villain, dreaming to walk out of their fathers' shadows and recovering their own agencies.

Although the deaths of the dads signify the end of a period of colonization, the aspirations for rebirth into real Chinese at the turn of the century prove to be apocalyptic anxieties. There is no reincarnation, only boundless suffering in the infinite inferno, which the film's title refers to in its epigraph invoked from verse 
nineteen of the Buddhist classic Nirvana Sutra: «The worst of the Eight Hells is called Continuous Hell. It has the meaning of Continuous Suffering». The Avinci or Continuous Hell is not a purgatory, where the fallen souls can possibly be purified through suffering; it is an abyss of incessant sufferings from kalpas to kalpas, which will never relieve one from the burden of guilt notwithstanding. The concept is reiterated in the prequel and sequel with more canonical citations that depict the infernal site as timeless, placeless, and with no exit.

Such is the situation of Hong Kong. In one and a half centuries, the colony has changed from a fishing village to an industrial town to an international city, and has shifted from an identity vacuum of its precolonial past to the identity disorder of its postcolonial present. Yet its colonial identity remains, and will ever be, unfixed. In an interview of the screenwriters, while Chong observes that the multiple roles Hong Kong people have to play in the post-British period are again doubled, Mak asserts, «Hong Kong is a place allowing no hero». ${ }^{18}$ And if there is one, it can only be - to use the description of Andy Lau's role by German film critic Dan Fainaru - a «dark, shady, ambiguous hero». ${ }^{19}$ Truly, it is as dark as the absolute hell, as shady as the characters' personalities, and as ambiguous as the normative citizenship.

\section{Double Identity/Troubled Genealogy}

Set from 1991 to 1997, Infernal Affairs II picks up the storyline from the first part's opening flashback, when young Lau (Shawn Yue) and Chan (Edison Chen) are cadet classmates at the police academy, whereas Sam and Wong are collaborators in manipulating the underground. Lau is infatuated with Sam's wife, also called Mary (Carina Lau), who instructs him to murder Sam's triad chief Ngai Kwun (Joe Cheung) at Wong's behest. Again, the female figure is at the center of gravity. Being the woman of the two father figures and admired by young Lau, Mary plays politics between the hostile underworld and police forces. At first, she appears to be a common ground where different identities have a share of their own interests, but when she bluntly refuses Lau's affection and shows ultimate loyalty to her endangered husband, she is betrayed to the Ngai family by Lau. Lau regards Mary's rejection as a denial of his status and thereafter makes up his mind to change it. It is after the unlawful death of the Chinese godmother in a traffic «accident» and under a standard portrait of Queen Elizabeth II, the British mother figure, that the

\footnotetext{
${ }^{18}$ Mak Siu Fai and Chong Man Keung, Wujiandao qianzhuan: Juben, bianju Iunshu (Infernal Affairs: screenplay with scriptwriters' commentary), p.34. ${ }^{19}$ Dan Fainaru, «Review of Infernal Affairs», at Screenplay.com (http://www.secreenplay.com/story.asp?storyid=11260), 2003.
} 
criminal-turned-constable provocatively proclaims his careerism in response to the promotion board led by the British officers: «I guess we will have to start all over again».

The prequel traces the first part's development of double identity back to a troubled genealogy. Young Chan finds himself an abandoned and illegitimate child of the assassinated gangland guru. The desertion is redolent of the three abandonments of Hong Kong in its colonial history: first in 1841, when Hong Kong Island was ceded by the Manchu government; then in 1941, when the British surrendered to the Japanese; and lastly in 1997, when London handed her crown colony over to Beijing. Thus, in Hong Kong as in other parts of the world, colonization is a continuous multi-hegemonic operation that takes place neither once nor twice, but thrice or more. It amounts to a heterogeneous genealogy, a lineage of nonidentity. Resisting his illicit identity, Chan is determined to cut off his consanguinity with the triad family by taking the surname of his mother - though she is absent in the film and becoming a policeman to arrest the Ngai's. Unfortunately, he is expelled from the school after his family background is unveiled. To negotiate his cadetship, Wong offers an indecent proposal: in order to disengage himself from the underworld, he must first engage in it; that is, to serve as a mole among the Ngai's, so as to sever himself from them. So, he has to start his life all over again as a gangster cast into a hell-like prison. While Wong plans to resign and leave Hong Kong after Ngai's case, Chan wishes to «return» (not as a criminal, but as a cop) and have his own desk in the police department, yet their enduring duties drag them on till their tragic deaths.

Chan is not alone in suffering from the obsession with identity. His half brother, Ngai Wing Hau (Francis Ng), who manages to ascend to the top seat in the triads with his cruelty and mercilessness, also desires to wipe out the blemish in his family history. The new godfather strives to become a political consultative candidate, hoping to rewrite the family saga on the threshold of dynastic change. He seizes the eve of the «liberation» as prime time to fix his identity, unaware of Chan's double-cross. Despite their individual purposes, the two brothers represent a collective consciousness of the need to change from what Indian Hong Kong scholar Ackbar Abbas describes as «a «floating» identity that has served Hong Kong so well in the past» to a «definite identity» to be established for «current political exigencies». ${ }^{20}$ Like the dismissal of Chan from the police school, Ngai's candidacy turns out to be a Cinderella dance at the ceremonial dinner on $30^{\text {th }}$ June 1997,

${ }^{20}$ Ackbar Abbas, Hong Kong: Culture and the Politics of Disappearance, Minneapolis: University of Minnesota Press, 1997, p.4. 
deadline of the Hong Kong dream. The playwrights choose the historical moment of «reunification», a time fraught with convivial tension, when Wong suddenly shows up at the banquet and presents an arrest warrant to the gangland kingpin. As invitations to celebration are withdrawn from him, Ngai's candidacy is revoked by the PRC's Hong Kong and Macao Affairs Office. Finally, when he kidnaps Sam who is willing to serve as witness against him, he is shot dead by Wong.

The mastermind's tragedy lies in his misunderstanding of the political «transition» (guodu) as not only a change of the sovereign power, but also his chance for a renewed identity. He misrecognizes the end of British jurisdiction to be an expiration of colonial control and, more mortally, a return to stainless strain at what he believes to be the best of times. The theme of the return is now presented as an anxiety of time in the tragic heroes' search of a lost - or, more precisely, an imagined - origin. Only before and after Sam's narrow escape from Ngai's killers in Thailand do Mary and Sam realize respectively that they have «passed the point of no return». The point of no return is dramatically documented at the end of the film, when all policemen and women change the emblems on their hats and in their station as the British flag is replaced by the PRC flag at the rainy handover midnight. Then the intense darkness of the night on $1^{\text {st }}$ July 1997 is decorated by dazzling fireworks to celebrate the «return».

\section{Hong Kong/Xianggang}

The identity crisis finally leads to schizophrenia in Infernal Affairs III, a sequel made up of multiple parallel cuts between flashbacks and flashforwards with obsessive interest in dates indicating temporal disorientation. Reining up the usual excesses of bloody violence of the Hollywood-style action genre, this last installment of the police epic is more of a psychodrama - with an ending evocative of the stunning schizy scenes of the overwhelming wall-postings in Ron Howard's A Beautiful Mind (2001) and Laetitia Colombani's He Loves Me . . . He Loves Me Not (2002) - and almost a ghost story. A year after Chan's death, Lau has been cleared of any charges in the case and starts to investigate the secret ties between chief inspector Yeung Kam Wing (Leon Lai), another rising star in the police force, and Shen Cheng (Chen Daoming), a mainland arms trafficker who wanted to build up a smuggling network with Sam three years ago. As the intricate plot develops, Lau, still obsessed by the proclamation «I'm a cop» and feeling insecure and paranoid about his career, gradually pushes himself into an abyss of mental disorder. He experiences a delusion of meeting with the departed Chan and Wong and an auditory hallucination of a phone call from Chan. When he looks at himself in the mirror and sees Chan's image instead, he smiles approvingly. Apparently, he is possessed by 
the spirit of Chan and projects his past self on Yeung; in other words, he is haunted by history and pursues his present self as the past other. However, in Dr. Lee's clinic, where both Chan and Lau confess the truth during hypnotherapy, yesterday and today, self and other all collapse into an identity black hole.

The film reaches its climax and complex when Lau leads his team to arrest Yeung. As the former shows evidence that only proves his previous collusion with Sam, he is actually acting as Chan to bust himself. But when Yeung announces himself to be a cop, Lau recalls the same self-identification by Chan a year ago. He suddenly turns around, counterclaiming that he himself is also a cop while shooting down Yeung. However, Lau kills not only Yeung, but also Lau's alter ego and his memory of Chan as well. As Shen fires at Lau, we see Yeung, Chan (in black and white), and Lau falling to the ground one after another. Lau's last bullet shot suicidally through his own upper jaw seriously damages his brain, leaving him in dementia. The penultimate scene has Lau unconsciously taping Morse code on his wheelchair in a hospital.

While the small or lower-case other comes from fission within oneself, there is also a capital or upper-case Other that imposes a total identity anew. When the mysterious limper Shen reveals his real capacity as an undercover commissioner from the mainland but still conceals his name symbolically as Shadow, he immediately poses himself to be the new father figure overshadowing the powerful Wong, Sam, and Ngai all at once. It is his pistol that gets Lau under control, meaning that he settles the unsettled forcibly. Representing the domiNation, the mainlander demands that his Hong Kong partners speak Mandarin, commands his Hong Kong subordinates to cuff Lau, and at the end, in front of Chan's and Yeung's graves under the national and regional flags, recommends Hong Kongers to recommence: «Let bygones be bygones. Tomorrow is another day». A neocolonial cliché, this last statement urges the listener to turn over a new leaf of history from English colonization to Mandarin recolonization. It echoes Chan's hope that «everything'll be OK after tomorrow», which is frequently repeated by Chan himself and his other self, Lau. Yet tomorrow is another tomb to follow.

The close-up of the five-star red flag highlights the fact that the China in question refers neither to an ethnical nation nor to a historical imagination, but to a political reality, an institutional entity known as the People's Republic of China. The banner of national identity and the sacrifices to group loyalty signify a Party endorsed patriotism that declares the state to be adequate to every individual's identity by easily simplifying the identity complex in the valance of fixed territoriality, sovereignty, and nationality. However, the strong Cantonese accent among native 
Hong Kong Chinese will preclude all closures of the cleavage between Hong Kong and Xianggang, just like the ever-existing colonial rift between Hong Kong and Heung-gong. Here, identity disorder manifests itself as language disorder, wherein Mandarin is less an official language for national unification than part of a lingua franca of the port city. For the people who speak Cantonese as their first language, Mandarin, like English, means a barrier of identification, a practice of discrimination (by the colonizer), before it becomes a (blockaded) bridge for communication. One wonders since Mandarin has never been their mother tongue, how come the mainland is their motherland. Indeed, it is in the «dialectic» (both linguistically and philosophically) sense that the colonial city Hong Kong goes global, and Xianggang goes postcolonial, whereas Heung-gong is unrecognizable.

\section{One Country/Two Systems: Heterotopia and Schizophrenia}

Noteworthy are the cemetery scenes in all three installments of the trilogy. It is in the cemetery, the entrance to hades, that young Chan submits evidence of his brother's crimes to Wong and requests a normalization of his identity (Infernal Affairs II), that Chan's police identity is recognized only after his death (Infernal Affairs), and that the mainland master inculcates his Hong Kong subject with the need to bury the past (Infernal Affairs III). The burial ground is so symbolic that Foucault used it as an example of «heterotopias» in a 1967 lecture. ${ }^{21}$ Foucault formulates the concept by employing the mirror metaphor: on the one hand, the mirror is a utopia, reflecting the image of oneself in a placeless place behind the surface where one is visibly absent; on the other, it is also a heterotopia, a countersite existing physically in reality, where one's self is reconstituted by seeing one's own gaze from the other side of the glass. Foucault suggests: «The mirror functions as a heterotopia in this respect: it makes this place that I occupy at the moment when I look at myself in the glass at once absolutely real, connected with all the space that surrounds it, and absolutely unreal, since in order to be perceived it has to pass through this virtual point which is over there».22 Accordingly, the modern cemetery appears as «the other city», a «dark resting place» for «the dead body, which is ultimately the only trace of our existence in the world and in language». ${ }^{23}$

I would like to add that it is between the real and the unreal, between the living (present) and the dead (past), and between the metropolitan language (whether it be English or Chinese) and the local dialect that «I» is torn apart. The heterotopia

${ }^{21}$ Michel Foucault, «Of Other Spaces», trans. Jay Miskowiec, vol.16, nº1, p.25.

${ }^{22}$ Michel Foucault, p.24.

${ }^{23}$ Michel Foucault, p. 25 
reveals our heterogeneity by exposing the otherness within. In effect, the heterotopic inhabitants are always preferably schizophrenic: half of a Chinese Hong Konger is British. This postcolonial psychological condition has been observed by Tu Wei-ming: «For the majority of Hong Kong residents, being Chinese as a British subject is, in human terms, arguably superior to being Chinese as a citizen of the People's Republic of China». ${ }^{24}$ Yet they cannot identify themselves with the Chinese or the British; they must be identified by their colonizers. Indeed, Hong Kong, be it a British colonial outpost or Chinese special administrative region, is a heterotopia rather than a «homogeneous society» as British scholar Matthew Turner believes it to be. ${ }^{25}$ Foucault describes a colony as a compensational heterotopia, a perfect and well-arranged space created as a contrast to the messy and illconstructed metropolis. ${ }^{26}$ The Asian trading center serves as a model for the declining British economy and now the other system under the so-called «one country, two systems» for the booming Chinese market. Nonetheless, being a colonial heterotopia, it deserves but heteronomy, because it would not have become the lustrous Pearl of the Orient had it not been cultured by the Orientalist hegemony, and now it can only maintain its glorious globality as a «Chinese» city without appealing for declaration of independence.

Furthermore, we must not forget that the film per se as a fantasmatic projection of reality also gives rise to a heterotopic space, namely, the cinema. It is through the reflection of their transnational filmic images on the screen that Hong Kong people at last discover themselves. Thus, the movie serves as a mirror of the split mind, whereas the theater is a schizo-scenic site of delusions and hallucinations. The film is a hallucinogen that at once precipitates and treats schizophrenia. It triggers the madness from the shattered minds of the moviegoers, symptomizes/cinematizes it, so that they can recognize and manage it in their stressful urban life.

Deng Xiaoping's architecture of «one country, two systems» may be a great invention in bridging the macro gap between communism and capitalism, but it does not address the micro fissure of identity cleft, because the concept itself is schizophrenic in nature. There is still a long distance between Hong Kongers' Chinese identity and their identification with China. The Infernal Affairs trilogy raises the issue of identity politics under the commercial camouflage of cops-androbbers thriller. The personal and collective quest for a legitimate Chinese identity

${ }^{24}$ Tu Wei-ming, «Cultural China: The Periphery as the Center», in Tu Wei-ming, ed., The Living Tree: The Changing Meaning of Being Chinese Today, , Stanford: Stanford University Press, 1994, p.11.

${ }^{25}$ Matthew Turner, «Hong Kong Sixties/Nineties: Dissolving the People», in Matthew Turner and Irene Ngan, eds, Hong Kong Sixties: Designing Identity, Hong Kong: Hong Kong Arts Centre, 1995, p.24.

${ }^{26}$ Michel Foucault, «Of Other Spaces», p.27. 
is perhaps desirable, yet doomed to failure because of betrayal. Such betrayal, as suggested by the moles' job nature, is derived from a duplicity that unsettles any monolithic identity. Since the former British colony has been denounced by Beijing as an «anti-communist base» for its protests against and annual vigils in remembrance of the 1989 Tiananmen Square massacre, the identity duplicity is translated into potential treason to the party-state. The central government, so phobic about the historical humiliation and recent resistance brought by Hong Kong (reminiscent of Shen's comment on his handicap caused by Chan in their gun battle), has pressed the local administration to legislate with a new internal security law. The Hong Kong-mainland relation, as the cooperation between Sam and Shen suggests is a suspicious and cautious one.

This explains why film critic Li Cheuk-to cites the series as a major example in his review of the political messages of Hong Kong's late movies: «The former colony's recent cinema continues to reflect its uneasy relationship with Mainland China and its uncertain future». ${ }^{27}$ The future is certainly uncertain as long as there is a continuous process of in-between mixture of colonialism and globalism and in-itself breakdown of nationality and identity. It is in such schizophrenic sense of identity that Hong Kong is transforming into a postcolonial global city.

${ }^{27} \mathrm{Li}$ Cheuk-to, «Journal: Hong Kong», Film Society of Lincoln Center (http://www.filmlinc/fcm/9-102004/hongkongjournal.htm), 2004. 